Florida International University FIU Digital Commons

$9-5-2000$

\title{
Social networks of immigrant preadolescents : network structure,sources of support, and psychological well-being
}

Gastón Luis Bustos

Florida International University

DOI: $10.25148 /$ etd.FI14052504

Follow this and additional works at: https://digitalcommons.fiu.edu/etd

Part of the Psychology Commons

\section{Recommended Citation}

Bustos, Gastón Luis, "Social networks of immigrant preadolescents : network structure,sources of support, and psychological wellbeing" (2000). FIU Electronic Theses and Dissertations. 1998.

https://digitalcommons.fiu.edu/etd/1998 
FLORIDA INTERNATIONAL UNIVERSITY

Miami, Florida

SOCIAL NETWORKS OF IMMIGRANT PREADOLESCENTS: NETWORK STRUCTURE, SOURCES OF SUPPORT, AND PSYCHOLOGICAL WELL-BEING

A thesis submitted in partial fulfillment of the

requirements for degree of

MASTER OF SCIENCE

in

PSYCHOLOGY

by

Gastón Luis Bustos

2000 
To: Dean Arthur W. Herriott

College of Arts and Sciences

This thesis, written by Gastón Luis Bustos, and entitled Social Networks of Immigrant Preadolescents: Network Structure, Sources of Support, and Psychological Well-being, having been approved in respect to style and intellectual content, is referred to you for judgment.

We have read this thesis and recommend that it be approved.

Nathalie Guacci-Franco

William Kurtines

Mary J. Levitt, Major Professor

Date of Defense: September 5, 2000

The thesis of Gastón Luis Bustos is approved.

Dean Arthur W. Herriott College of Arts and Sciences

Intérión Dears Samuel S. Shapiro Division of Graduate Studies

Florida International University, 2000 


\section{DEDICATION}

I dedicate this thesis to my parents, my sister, and my wife. Without their

patience, understanding, support, and most of all love, the completion of this work would not have been possible. 


\section{SOCIAL NETWORKS OF IMMIGRANT PREADOLESCENTS: NETWORK STRUCTURE, SOURCES OF SUPPORT, AND PSYCHOLOGICAL WELL-BEING by}

Gastón Luis Bustos

Florida International University, 2000 Miami, Florida

Professor Mary J. Levitt, Major Professor

This study explored social network characteristics and sources of support for immigrant and nonimmigrant preadolescents. The relation between social support and psychological well-being for these children was also addressed. Participants were 782 preadolescents, including 172 immigrants, of diverse income and backgrounds. Students completed the social convoy mapping procedure, answered social support questions, and completed the short form version of the Children's Depression Inventory, the Loneliness Scale, and Self Perception Profile. Immigrant children perceived significantly less total support and close family support than did nonimmigrants. Immigrant children's levels of well-being were significantly lower. Close Family Support was an individual predictor of depressed affect. Extended Family Support and Friend Support were predictors of loneliness; with extended family support having a stronger relationship for immigrant children. Close Family Support and Friend Support were predictors of Self-Concept. In sum, the findings highlight the importance of family support on the well- being of preadolescents. 


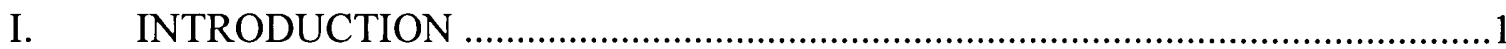

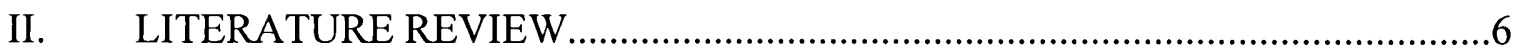

Well-being of Immigrant Children and Adolescents............................................6

Family variables and well-being of immigrants.............................................10

Social Support in Immigrants...........................................................................18

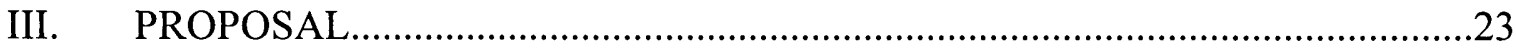

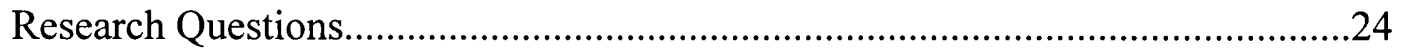

IV. METHOD

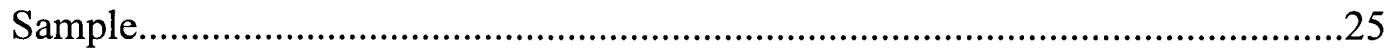

Procedure

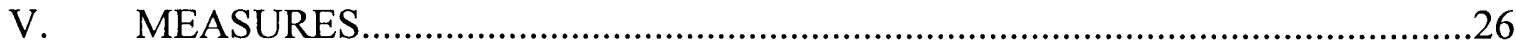

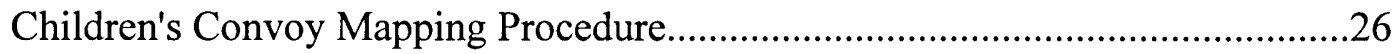

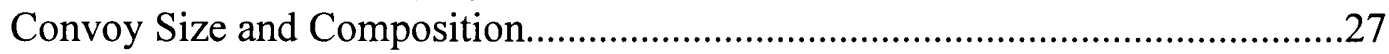

Total Support and Specific Sources of Support..................................................28

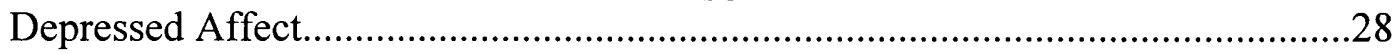

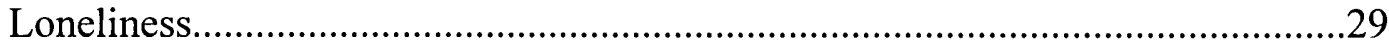

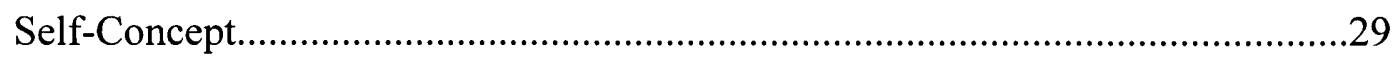

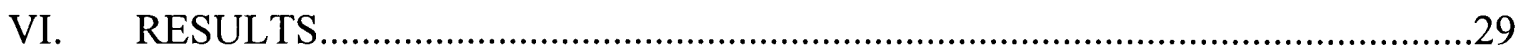

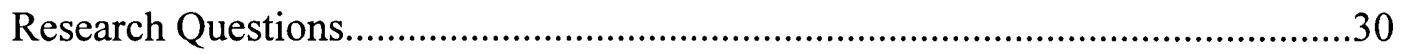

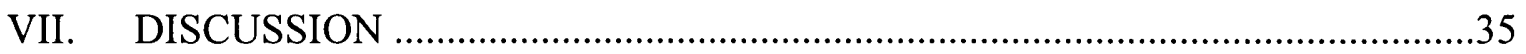

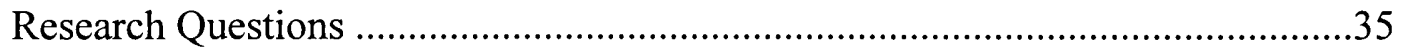

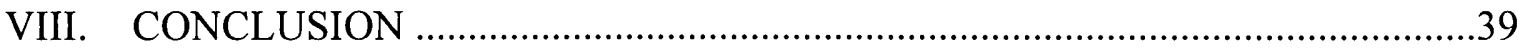

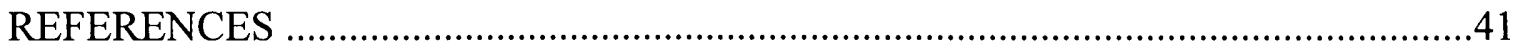

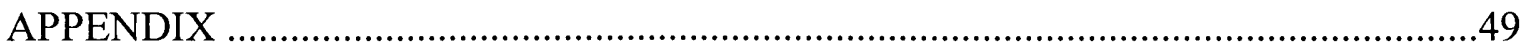


Since its very beginnings as a nation, the United States has been made up mostly of people from other places. Dating back to the 17th century, they came from Europe to seek wealth as the only way to success (Britannica Online, 2000). Three centuries later the concept is the same; immigrants come to this country to improve their lives. However, today success can mean a number of things and immigrants come from all over the world. People leave their homes in places like Asia, Africa, and South America to seek freedom, education, and availability of resources. As a nation, this has placed the $U$. S. as one of the world leaders in providing opportunities for its new citizens to reach their objectives.

Today there are an estimated 20 million foreign-born immigrants living in the United States. The countries of origin and reasons for departure of the first immigrants are different from those of today. Until the first half of the 1900's, most were from Western Europe. Changes in world economy, immigration policies, and an increased preference for familial- and skill-based selection of immigrants made Asia and Latin America responsible for 85 percent of the immigrant population by the 1980's (Martim and Midgley, 1994). In order, the top countries of origin were Mexico, the Philippines, Vietnam, China, and Korea. The sum of all immigrants from the Caribbean (e. g., Dominicans, Jamaicans, Cubans, and Haitians) would put this geographical region in second place in the list (U.S. Bureau of the Census, 1994).

The substantially increasing proportion of the immigrant population with respect to natives of the United States is most noticeable in the younger cohorts. Children of 
immigrant families are expanding in numbers more rapidly than their American

counterparts. From 1990 to 1997, the number of immigrant children grew by almost 50 percent, while that of children of parents born in the United States grew by only seven percent. In fact, by 1997, twenty percent of the children in the United States were immigrants (Hernandez \& Charney, 1998). This percentage is expected to increase to 50 percent by the year 2030 (Day, 1996). Immigrant children already are the majority in many schools, neighborhoods, and cities across the country.

Research in child well-being and emotional adjustment has increased dramatically in the last few decades. Children's feelings of loneliness, self-concept, and depression are dimensions of psychological well-being that have received much attention (Canino, Early, \& Rogler, 1980; Shuval, 1982; Aronowitz, 1984). Researchers have also become keenly interested in the relationship between children's social relationships and emotional adjustment (Bronfenbrenner \& Crouter, 1983; Dunn, 1993).

Social networks have been initially studied with adults (Antonucci, 1990), but their study in conjunction with social support and children's well-being is in its developing stages. It is only recently that this area of developmental psychology has blossomed (Belle, 1989; Cochran, Larner, Riley, Gunnarsson, \& Henderson, 1990; Levitt, Guacci-Franco, \& Levitt, 1993). Today the amount of research in this area is limited, but it shows a promising future. Studies of social support and psychological well-being of immigrant children are even less prevalent. In the past, immigrant samples were less available to researchers and findings on immigrant children were difficult to generalize to mainstream America. Today, however, given the dramatic rise in the population of child 
immigrants and children of immigrants, research on the social forces that affect emotional well-being in this population is in greater need than ever before. The present study attempts to contribute to the foundation of this emerging area of research.

Immigrant and native children are no different with respect to their basic needs. The importance of availability of resources that serve as a foundation for successful child development cuts across political and cultural borders (Alatorre Alva \& de Los Reyes, 1999). All children share the necessity of elements for physical and emotional protection. Proper housing, nutrition, clothing, vaccinations and health care, social and emotional support, schooling, and recognition of these needs from legislators are important elements in the complex interplay of forces affecting child development.

Although all children have basic needs, immigrant children may be at a disadvantage. Their lives are faced with a nonnormative event with the power to influence their families' ability to obtain tangible and intangible goods. There are a number of factors associated with migration that can influence how families adapt to life in a new culture. These factors may be influenced by political and social institutions in the form of legislation, by personal characteristics such as belonging to a particular ethnic group or race, and by the dynamics within the family (Booth, Crouter, \& Landale, 1997).

With the increasing heterogeneity of immigrants it has become more complicated to conclude who is at an advantage or disadvantage. Today's immigrants are from many socioeconomic, ethnic, political, cultural, and educational backgrounds. Factors likely to benefit those who migrate have been identified, but they are unlikely to be uniformly shared across certain groups of individuals (Guerra \& Jagers, 1998; Rumbaut, 1997). 
Likewise, different factors associated with negative adjustment may affect different people differently.

Most immigrant children living in densely populated cities across the country are minorities, usually Black or Hispanic, and of low income. They are a group that has to face the cumulative adversities of low income and immigration. Living in a low income neighborhood puts the child's physical as well as psychological safety at risk. Children from poor families are more likely to experience depression, low self-esteem, health problems, and to be aggressive (Canino, Early, \& Rogler, 1980). In the case of immigrant families, secure employment may be difficult to find and caregivers may have no option but to work multiple jobs with irregular hours. This can result in an impediment for parents to provide adequate and consistent support for their children (Igoa, 1995), a vital necessity for the children's well-being in any period of their lives.

Some immigrant families are obligated to adopt a new system of life more limited and with fewer available resources. In some cases, the family has to relinquish the lifestyle of the old country for one with lower living standards, and adults are forced to give up their professional credentials and careers that would allow for an easier transition. It has been found that this type of shift can impact the children's well-being even when temporary (Kopala, Esquivel, \& Baptiste, 1994).

The home may also be a setting for stressful events in the context of family dynamics (James, 1997). Immigration suspends or discontinues family and social networks in many families. Parents, siblings, extended family members, and other significant people may be left behind and their support is consequently out of reach. This 
may be especially critical for adolescents who experience prejudice, obstacles due to language differences, and dissonance of self-identity. Furthermore, according to the convoy model of social support (Levitt, Guacci-Franco, \& Levitt, 1993), the composition of the supportive network of a preadolescent may be different from that of an adolescent. Preadolescents are more likely to seek support from extended family members while adolescents are more likely to seek support from their peers. The impact of people absent from the network should be observed developmentally and in relation to the life stage of the child (Eisenbruch, 1988; Laosa,1989).

In sum, immigrant children and their families have to deal with a variety of issues. Some of these are part of the normative development of the family as a unit and others are the result of the nonnormative transition of migration and adaptation to a new culture. In addition, each family member is dealing with his or her normative and nonnormative development as well. The study of immigrant children and their lives brings new challenges to the scientific community. Studies have shown that the generalization of findings across groups has become increasingly difficult and that different groups of people may have different socialization processes, family dynamics, or life experiences. There is a particular need to study the social networks of immigrant children and how variations in the availability of social support affect immigrant child well-being. In the present proposal, preadolescent immigrants, children of immigrants, and nonimmigrants will be compared on a number of social network and well-being measures. The following sections of this proposal will outline previous research on immigrant children and related issues. The first section will summarize findings on the well being of immigrant children 
and adolescents. The second section of will be a review of the literature on family variables and their effects on well-being of immigrant samples. The third section summarizes the literature on social support in immigrant samples. The fourth section is a description of a proposal for the study of immigrant preadolescents' social networks, social support, and well-being. The specific aims of this proposal will be delineated, followed by the proposed methodology and data analysis for this study.

Well-being of Immigrant Children and Adolescents

The welfare of individuals has always been a major focus of psychological research. As new methods are developed, theories created, and populations studied, boundaries are pushed back and discoveries are made. The study of immigrant children's well-being is relatively new, and each discovery brings a new set of challenges. Although some researchers have not found differences in well-being between immigrants and nonimmigrant child samples (Fuligni, 1998; Weinberg, 1979), others have reported lower well-being in immigrant children (Baptiste, 1993; Cornille \& Brotherton, 1993). This section summarizes findings on the well-being of immigrant children and adolescents.

Rousseau, Drapeau, and Corin (1996) studied the relationship between academic achievement, learning difficulties, and emotional problems in refugee children as perceived by their teachers and parents. The authors were interested in the use of learning difficulties as an indicator of emotional problems. Children were selected through cluster sampling. They were between the ages of eight and twelve, born outside of Canada (the host culture), and from Southeast Asia or Central America $(\mathrm{N}=156)$. 
Parents completed the CBCL and teachers and school officials were surveyed about the existence of learning difficulties in the immigrant child population. Academic achievement was measured through grade point average and standardized test scores. Correlational analyses were the statistical tool of choice. The two groups had comparable GPA's, but Central American children were rated as having more learning difficulties. School officials saw Central American children as having more learning difficulties and rated their behaviors as more extroverted and hyperactive. The global score for externalizing problem behaviors was related to learning difficulties for both groups. The researchers questioned the factors that influenced the school authorities' ratings of the children, without discarding a possible bias. The researchers' aim of predicting emotional problems via school achievement was not supported. Furthermore, the assessment of internalized symptoms, which may be masked by cultural expectations, may have been better assessed via self-reports.

Pawliuk, Gritzenko, Chan-Yip, Gantous, Mathew, and Nguyen (1996) observed children of immigrants' psychological functioning in relation to social variables related to immigration. The sample consisted of 23 boys and 25 girls from six to seventeen years of age $(M=11.7)$ of various ethnic backgrounds and socioeconomic status. Eleven of the children were first generation immigrants. Children completed a modified version of the Bicultural Involvement Questionnaire (alpha=.67) developed by Szapocznik, Kurtines, and Fernandez (1980). They also answered self-reports to assess depression, anxiety, and psychosomatic symptoms. Parents completed the Child Behavior Profile (Achenbach \& 
Edelbrock, 1983) to provide sociodemographic information, such as family relationships, and their children's internalizing and externalizing behaviors.

Results concerning psychological functioning indicated that 23 percent of the sample showed extreme behavioral difficulties, according to parent reports. Forty percent of the children were rated by their parents in the clinical range of the social competence subscale. According to self-reports, 63 percent of the children scored lower than the self-esteem scale average. In addition 23 , percent of the sample scored in the clinical range for depression. The authors propose that the immigrant child's feeling of alienation may be better assessed with measures of internalizing and covert behaviors.

Psychological well-being and educational achievement of immigrant adolescents were analyzed for the 1988 data of the National Education Longitudinal Study (NELS) (Kao, 1999). The first focus of the analysis was on the possible differences between first, second, and third generation immigrants for the outcome variables. The second focus was the determination of to what extent these differences could be explained by the children's previous education, problems with the English language, problems learning, and involvement in specialized programs. Lastly, the relationship between generational differences in well-being and academic performance were observed. The subsample used was composed of 24,599 eighth graders and was selected due to its oversampling of Asian and Hispanic students, large number of recent immigrants and minorities, and the participants' involvement in the school system. Psychological well-being was calculated with locus of control, self-concept, and alienation measures. Math and reading standardized test scores and GPA were indices of academic achievement. 
Well-being scores of immigrant children were compared against a baseline score determined by that of third generation White students. Results for locus of control indicated significantly lower levels for immigrant Asians, Hispanics, and Blacks. Similarly, immigrants of all racial and ethnic backgrounds reported feeling alienated. Low self-efficacy (locus of control) was determined to be associated with absence of English as home language, poorer grades, and negative school experiences (i e., skipping classes or repeating a grade) for Hispanic and Black students. Feelings of alienation, while significant across immigrant groups, were associated differently to predictor variables; Asian and Hispanic first and second generation students were more likely to feel alienated. Reported self-esteem showed minor group differences even after controlling for SES; adolescents with absence of English as home language were more likely to report lower levels. As reported in previous studies, there was a negative relationship between immigrant generation and academic achievement.

Vega, Khoury, Zimmerman, and Gil (1995) analyzed data from a longitudinal study in the South Florida area to learn how sociocultural and psychological factors affect the behavior of immigrant adolescents. Since one of the study's main interests was the assessment of illegal drug and alcohol use among Hispanic adolescents, which is significantly low among female Hispanics, only male subjects were selected. Hispanic, non-Hispanic White, and African-American students $(n=2,360)$ were interviewed and their parents and teachers completed the Child Behavior Checklist (CBCL). Ethnic background and level of acculturation problems were designated as predictor variables and parents' $\mathrm{CBCL}$ and teachers' $\mathrm{CBCL}$ scores as outcome variables. 
ANOVA's for parents' CBCL scores were significantly lower for Cubans and higher for African-Americans, respectively. Hispanic subgroups (i e., Puerto Ricans, Colombians, Nicaraguans, Cubans, and other Hispanic) did not have significantly different scores among themselves or compared to the other groups, although they were lower. Teachers' CBCL scores indicated more behavioral problems for Puerto Rican and African-American students, while the only group to score significantly higher than the others in the clinically derived measure was African-American.

Acculturation problems and well-being for first and second generation Hispanic adolescents were examined. Foreign-born Hispanics' only significant source of acculturation stress was language problems and it exceeded clinical levels in both the teachers' and parents' CBCL. U.S.-born Hispanics' ratings of the CBCL did not show significant sources of stress, while the TRF indicated three. Language conflicts, perceived discrimination, and perception of a closed society (above the clinical level) were significant sources of stress. Acculturation conflicts was not. Parent-reported behavior problems were present only for first generation students, and teacher-reported problems for both first and second generation immigrants. SES and sociocultural differences among the Hispanic groups did not affect the results significantly.

Family variables and well-being of immigrants

The family is one of humankind's institutions. Through the centuries it has evolved together with its members to accommodate their welfare and survival needs. The family can serve as a shelter as well as a base for rehearsal and preparation for the challenges of the world. Family dynamics are not uniform across individuals, and they 
may impact people differently. The following is a review of studies concerning family variables and what role these play in the well-being of immigrants.

De Santis and Ugarriza (1995) did a descriptive study of the differences between Cuban and Haitian families living in the U.S. They recruited 30 Haitian mothers and 30 Cuban mothers from the South Florida area. Mothers' length of residence in the U.S. was not to exceed four years and their children were not older than adolescence. Mothers completed a questionnaire of sociodemographic characteristics, household structure and function, concepts of child health and illness, and childrearing beliefs and practices. Results indicated that all Haitian families were nuclear while 23 percent of Cuban households included extended family members. Seventeen percent of the Cuban families shared household and child responsibilities with extended kin. Cuban mothers' viewed familism as central in family functioning. The family is an interdependent unit that can serve as the source of tangible (e.g., employment opportunities, instrumental assistance) and intangible resources (e.g., support, love). Haitian mothers expect their children to be subordinate and respectful of elder kin. Obedience and respect for authority cultivate a sense of interdependence among family members as well as cooperation and noncompetitive behavior. However, all mothers believed American values and customs to be considered factors for intergenerational conflict. The more children acculturate, the more autonomous, individualistic, and nonfamily centered they become. The authors also indicate that Cuban and Haitian families' ability to rely on their extended members for assistance and support is a significant advantage, and families unable to do so may face distress, particularly for its children. 
Munroe-Blum, Boyle, Offord, and Kates (1989) studied child immigrant status in Canada as a predictor of child psychiatric disorder, school performance, and service utilization. Subjects were 2852 children ( 251 immigrants) aged 6 to 16 from the Ontario Child Health Study living in urban and rural areas. Gender was evenly distributed $(\mathrm{M}=1443, \mathrm{~F}=1404$, missing=5). Surveys were conducted with the female head of household of each child. The surveys measured psychiatric disorder with a checklist of items based on the Child Behavior Checklist (CBCL) and DSM III criteria. Child school performance and service utilization outcomes also were derived from the survey. Results indicate that immigrant children were two times more likely than nonimmigrants to live on low income, be at higher risk for social disadvantage, and live in over crowded conditions. They were also one and a half times more likely to experience family dysfunction. Logistic regression analysis indicated that there were no differences for academic outcomes, and immigrant children were less likely to use health services. Immigrant status did not make an independent contribution to psychiatric disorder but family dysfunction did. The criteria used to diagnose psychiatric disorder in this study were based on clinical measures and therefore had a higher cutoff than would a measure based on non-clinical populations. The relationship between family dysfunction and well-being in immigrant children needs to be explored further with a detailed description of family characteristics, such as perceived support, and well-being measures that can assess significant differences without clinical standards.

Gil, Vega, and Biafora (1998) conducted a longitudinal study to determine how illicit drug use is associated to family structure and environment with a sample of 3413 
African American, White non-Hispanic, and U.S.-born and foreign-born Hispanic boys. The participants completed questionnaires at three different times progressively from middle school to high school. The boys were placed in four different family structure categories: two parent family, single mother family, mother and other adult family, and changed family. Drug use was measured through a dichotomous variable and only subjects who were not users at Times 1 and 2 but were at time 3 were included in the analyses. Family pride (alpha $>$.87) and family cohesion (alpha $>.77$ ) were assessed by reliable measures previously used by the researchers. Family communication was also used to assess family environment.

Results showed that foreign-born Hispanics and non-Hispanic White adolescents were more likely to live in two-parent families. African Americans and U.S.-born Hispanics were most likely to live in single mother households, and foreign-born Hispanics the least likely. Illicit drug use initiation was least likely among adolescents of two-parent families. For adolescents from single-parent families, high drug use initiation was most common for U.S.- and foreign-born Hispanics only. Family factors were significant for all groups, having their strongest effects on drug use initiation for foreign-born Hispanics. This effect was related to the foreign-born Hispanic group having the highest rate of family deterioration from Time 1 to Time 2. Logistic regressions were used to determine the relationship between drug initiation and deteriorating changes in family variables for all groups. For U.S.-born Hispanics, there was a significant relationship for family variables at Time 1 and drug use. For foreign-born Hispanics, there was a similar relationship as well as one between drug use 
and change in family variables from Time 1 to Time 2 , with decreased family pride as the strongest predictor.

Health status and risk behaviors of immigrant adolescents were assessed in a massive project that included 20,000 adolescents in grades 7 through 12 . The National Longitudinal Study of Adolescent Health (Add Health) was conducted in 1995 to gain insight into the physical health, emotional health (i e., psychological distress and positive well-being), and self-reported risk behaviors of first, second, and third generation immigrants (Harris, 1999). First generation immigrants were those who were born in a foreign country, second generation immigrants were those who were born in the U.S. but whose parents were born in a foreign country, and the third generation were those born in the U.S. and whose parents were also born in the U.S. Third generation subjects were grouped with natives of the U.S., for their time in the U.S. is expected to have Americanized them to a level not significantly different from that of non-immigrants. Items from the CES-D Scale and Beck Depression Inventory were used to create two measures of emotional health. The first was a 15 item measure of depressive symptoms and the second a four item measure of positive well-being. Parents of 17,394 adolescents were interviewed at home to assess the structural and supportive properties of the family, its income, mother's education, and parental supervision. Family structure described parental or guardian figures. Support was defined as a combination of income level and parental supervision.

Results support a linear pattern of assimilation that can be observed by generation with changes in degree of physical health and risk behaviors. First generation immigrants 
had significantly less physical problems and engaged in significantly less risky behaviors than second generation immigrants. Second generation immigrants had significantly less physical problems and engaged in significantly less risky behaviors than third generation immigrants. Results for emotional health, while lower for first generation immigrants, were not significant. Furthermore, the strong relationship between place of birth and physical health and engaging in risk behaviors was not reduced after controlling for family context. Another relevant finding was that of second generation children being likeliest to live with their biological parents, third generation children the least likely, and first generation children between these two. This is an area that deserves further inquiry. The author concluded that foreign birth acts as a protective factor, regardless of country of origin and place of birth. The author also indicated the need to study a number of mechanisms potentially responsible for this protective effect (e.g., the children's extended kin relationships, parenting behaviors, social networks, and social support).

The Children of Immigrants Longitudinal Study began in the Spring of 1992 (Time 1) and concluded in 1996 (Time 2). The San Diego Longitudinal Sample is a subsample of this major study that was examined to learn about the relationship between sociocultural factors and psychological adjustment of immigrant children (Rumbaut, 1999). Rumbaut analyzed Time 2 data which came from 2063 adolescents attending school in the area. Participants were interviewed at school and 90 percent were of Mexican, Filipino, or Vietnamese background. The adolescents were first (39\%) or second (61\%) generation immigrants. They provided personal information that was utilized to predict psychological well-being. The predictor variables were (1) gender, 
national origin, age at arrival; (2) intrafamilial context and stressors; (3) extrafamilial context and stressors; (4) achievement aspiration; (5) and physical appearance and popularity with the opposite sex. Well-being measures of self-esteem and depression were assessed via the Rosenberg and CES-D scales, respectively.

Initial findings reported a negative relationship between length of stay in the U.S. and number of people living in the household. Length of stay in the U.S. was also negatively related to the child living with both natural parents; this was most noticeable with the Mexican group. Significant gender differences were also found, with females more likely to be depressed and to have lower self esteem. Family structure and relations were significantly associated to well-being and academic achievement; children who lived with both natural parents and scored lower on parent-child conflict were better adjusted and had higher GPA's. Familism was found to be generally higher for first generation than second generation immigrant adolescents. Familism also showed a decline with length of stay in the U.S., supporting the notion of the salient role of individualism in American culture. The only Hispanic group of the sample, Mexicans, showed high family cohesion and familism and low parent-child conflict in first generation data, but reported average cohesion and conflict in second generation data. Ensuing multiple linear regression analyses examined the independent effects of the five predictor variables on self-esteem and depression. The entire sample showed significantly high levels of depressed affect and self-esteem. From the first set of variables, age at arrival showed a positive relationship with depression, with those who recently migrated being more depressed. Filipino and Vietnamese children had lower 
levels of self-esteem. Intrafamilial factors were the strongest determinants of self-esteem and depression; parent-child relations had the most significant effect. Family structure emerged as a protective factor against depression. Extrafamilial factors (e.g., unsafe school, teachers' fairness) were related to depression only. Achievement aspirations were also related to self esteem. Satisfaction with one's looks and popularity with the opposite sex showed positive relation with self-esteem and negative relation depression.

Short and Johnston (1997) examined the influence of family variables on children's adjustment after immigration. The stress-buffering model was tested in a sample of immigrant Chinese children and their mothers. Families that had migrated no earlier than 1993, had a child, and were of Chinese background were included in the sample. Mothers completed home surveys that included the Hassles and Uplifts scale, Mother Immigration Stress scale (MIS), CES-D [depression] scale, Symptom Checklist-90-Revised (SCL-90-R), Multidimensional Scale of Perceived Social Support, Parent Support Scale, and CBCL. Surveys were translated to Chinese script by seven bilingual mental health professionals. Ninety seven mothers of 55 girls and 42 boys returned complete questionnaires. The average child age was eight and all participants lived in Canada.

In general, children of this study did not score differently in the number of behavior problems from nonimmigrant children their age. As hypothesized by the researchers, immigrant children whose mothers reported low levels of stress and distress had fewer adjustment problems. Regression analyses indicated a relationship between maternal support (support perceived by the mother) and girls' outcomes, but maternal 
support acted as a protective factor for boys only in the presence of family stress. On the other hand, maternal distress was not buffered by any variable for either boys or girls, but acted as a significant predictor of boys' behavioral adjustment. There was also an unexpected interaction: the higher the mother's perception of social support from her social network, the stronger the relationship between mother's distress and boy's behaviors.

The authors denote the inappropriate generalizability of the results to other immigrant groups. They also warn against the subjectivity of the mother's self reports which may contrast with the opinions of other family members. Furthermore, Short and Johnston suggest the inclusion of other family variables and or child variables. It is also important to note the lack of covert subjective behaviors and experiences of the children in this study.

\section{Social Support in Immigrants}

Our awareness of human beings' need for social contact and relations is as old as our self-perception as social beings. We are social beings and therefore need others in our lives. We are able to provide and depend on those who are or are not our kin. Differences in preference regarding exchange for support have evolved as we have evolved as a social species, and the mechanisms responsible for these preferences are complex and often associated with a specific situation and one's customs. The following section will outline the literature on social support in immigrants.

Golding and Baezconde-Garbanati (1990) investigated ethnicity, culture, and social resources as predictors of social integration and social support. Data were from a 
larger study conducted by the National Institute for Mental Health. Interviews were conducted with 3131 adults residing in California. Subjects were 538 U.S.-born Mexican-Americans, 706 Mexico-born immigrants, and 1149 U.S.-born white Americans. Regression analyses showed that Mexico-born immigrants had social networks that emphasized spouse and children the most, were more likely to be married, and less likely to contact relatives outside the household. Mexico-born immigrants also reported less emotional support from their social networks. Differences in support from relatives was significant for Mexico-born immigrants only (younger subjects were less likely to receive support). The authors add that high regard for the family may result in distress if it is absent or fragmented. They also suggest further research targeting cultural differences in social network characteristics and how these relate to well-being.

Gil and Vega (1996) conducted a study of stressors due to acculturation and how these relate to family dynamics. The sample was limited to Cuban and Nicaraguan children and one of their parents. The 674 Cuban and 211 Nicaraguan middle school students (6th and 7th grade) were from various schools in the South Florida area. Students were interviewed at school and parents by telephone. Measures assessed acculturation stress, family pride, familism, parent/child conflict, and family cohesion. Adolescent data showed that, overall, 25 percent of Cubans and 34 percent of Nicaraguans reported acculturation [family] conflict, which was positively correlated with acculturation level. Familism and acculturation for adolescents were positively correlated with time in the U.S, while family cohesion (parent-reported) was negatively correlated. These correlations indicate that the family's importance as a source of support 
increases with time spent in the U.S. and increased acculturation [family] conflict. At the same time, however, familial bonds seem to dissolve. This change in family cohesion (e g., wanting to spend free time with a family member) reported by parents may be related to the children's age. Children's social networks change according to life experiences, and this sample is in its preadolescent stage, which is a transition from focus on family to focus on peers and the development of new relationships. Furthermore, the decrease in family cohesion, the increased need for family support, and the increase in [family] acculturation conflicts call for research in this area. Namely, studies are needed regarding sources of support of immigrant preadolescents taking into consideration kinship beyond the nuclear family and fragmented networks due to migration.

In an effort to examine psychosocial stressors and coping responses of a Hispanic sample, Padilla, Cervantes, Maldonado, and Garcia (1988) interviewed a group of Mexican and Central American immigrants. Adult respondents (mean $=34$ years) who had been living in the U.S. for less than ten years completed a stress and coping open-ended interview. After the general stressors and coping questions, the 31 males and 31 females also completed the anxiety and depression subscales of the SC-90-R.

The authors employed a content analysis method to assess each interview individually. Language problems and not having a job were the most common stressors for both males and females. When asked about the coping response for language problems for Hispanics in general, 59\% mentioned taking English classes, but when asked about their personal coping responses, only four responded with studying as the solution; listening to others was the most common response. The most common personal 
response to dealing with the need of a job was to depend on family and friends.

Psychological well-being measures showed slightly, although not significantly, higher scores for depression and anxiety for the Central American sample. There was, however, a significant gender difference indicating much higher levels of reported depression for males. Self-esteem was significantly higher for those with higher proficiency English. Self-esteem was also, although not significant, the strongest predictor of both depression and anxiety.

Keefe, Padilla, and Carlos (1979) conducted a three-year longitudinal study on the function of the extended family as a support system with a Mexican-American sample. The study had three data collection points. Time 1 data for 666 Mexican-Americans and 340 Anglo-Americans with a mean age of 42 were reported. Participants were interviewed for an average of 25 minutes. These interviews showed a marked difference in local extended-family integration for the Mexican-American and Anglo groups. While 9 percent of Mexican-Americans and 54 percent of Anglos indicated no kin present, 30 percent of Mexican-Americans and 1 percent of Anglos reported high integration. Furthermore, Mexican-Americans were significantly more likely than Anglos to use kinship as a source of emotional support about an emotional problem. This finding was still significant after controlling for proximity; Anglos were less likely to have kinship networks or family members in the area. Mexican-Americans consistently relied on family while Anglos sought support from family and friends even when family support was available. Both groups relied on the extended family, but Anglos tended to approach 
friends, neighbors, and co-workers significantly more. Real kin were the primary source of support for the Hispanic group.

Sources of support for school related issues were examined for a group of Hispanic adolescents (Morrison, Laughlin, San Miguel, Smith, \& Widaman, 1996). Participants were 698 students in grades seven and eight. They answered a questionnaire of school related concerns (e.g., getting along with students, looks, getting along with family members, getting along with teachers, etc.) and the person(s) (parent, peer, teacher, etc.) with whom they are most likely to talk about each concern. The students attended a predominantly Hispanic (62\%) school in California.

Results for issues of greatest concerns for the students place getting along with other students, schoolwork, looks, getting along with family members, and getting along with teachers as the top five. Peers and teachers were the most common source of support for problems getting along with other students. Teachers and parents were the preferred sources of support for dealing with schoolwork concerns. Peers and siblings served as sources of support for problems with one's looks. Parents were sought when concerns were related to getting along with a family member. Issues of dealing with teachers were most often discussed with parents. Boys were more likely than girls to choose nobody as source of support. Girls were more likely to approach teachers and less likely than boys to consult parents. In general, parents and teachers were the primary sources of support. The authors conclude with the possibility of this sample's limited peer network as a result of their immigrant status and their traditional preference for authority figures for dealing with the issues discussed. 


\section{Summary}

In sum, previous research has shown that immigrant children's psychological well-being is associated to a number of social factors. Immigrant children's psychological well-being may be associated with social networks variables such as family structure and the availability of extended kin. Social support also emerged as a potential influence in immigrant children's well-being. Immigrant families prefer interdependence and cohesion among their members, and the need for family support appears to increase over time in immigrant children. Thus, differences in family support may be especially predictive of well-being. In addition, research suggests that there may exist differences in social network and well-being variables from immigrants to nonimmigrants.

\section{Proposal}

The proposed study was designed to explore social network characteristics and sources of support for immigrant versus nonimmigrant children. The relation between social support and psychological well-being for these children was also addressed. Preadolescence is a time in human development where individuals are capable of judging, interpreting, and responding to life experiences. They also respond to the feelings brought about by life experiences. In the case of immigrant children, there is a cumulative effect of challenges from both normative and nonnormative circumstances. Normative challenges include those associated with the expansion of peer and friend networks. Nonnormative challenges associated with being an immigrant, such as the absence of a loved family member, may contribute further to negative psychological adjustment. 
Immigrant children are likely to have a higher proportion of family members relative to friends in their social networks, given the familistic orientation of immigrants noted in the literature. Immigrant children may also have more difficulty establishing relations with peers. However, the literature is unclear about the impact of immigration on the social networks of child immigrants, the availability of support sources, and the extent to which variations in support are related to well-being. In this context, the following research questions were posed.

Research Question 1. What is the size and composition of social networks of immigrant versus nonimmigrant preadolescents? It is hypothesized that immigrant children will have a smaller number of people in their networks than monimmigrants based on the likelihood of family members having been left behind in their country of origin.

Research Question 2. What is the amount and what are the specific sources of perceived social support in relation to immigrant status? It is hypothesized that immigrant children will perceive less total support than their nonimmigrant peers. It is also hypothesized that immigrant children will perceive less support from extended family members than will nonimmigrants, as it is usually nuclear family members who migrate first. Other relatives may follow after some time, sometimes after a generation. Immigrant children's sense of familism and family interdependence, coupled with lesser availability of extended family members, may be reflected in their perception of limited amounts and sources of social support.

Research Question 3. Are there differences in levels of well-being across immigrant status? It is hypothesized that immigrant children will have lower levels of well-being 
than nonimmigrants. Reduced sources of social support along with the challenges of adapting to a new culture and school system may be mirrored in their well-being, specifically depressed affect and feelings of loneliness. Immigrants' self-concept scores are not expected to differ significantly from nonimmigrants', however, regardless of levels of support (Rumbaut, 1999; Vega \& Rumbaut, 1991).

Research Question 4. To what extent are the differences in levels of well-being a function of perceived social support? It is hypothesized that children with lower levels of perceived social support will score lower on the psychological well-being measures. This relationship may account for lower well-being in the immigrant group.

\section{Method}

Sample

Participants are part of a larger study (Levitt et al., 1998) that includes $782(31 \%$ African-American, 29\% European-American, and 40\% Hispanic-American) fourth and sixth grade students. Gender distribution is well balanced with $51 \%$ of the sample being female. Participants were drawn from eight public elementary schools in Miami-Dade County, Florida. Four schools were located in areas of economic distress and four were located in middle-income areas. There are 172 immigrants in the sample (36 African-American, 111 Hispanic-American, and 25 European-American). Of the 610 nonimmigrants in the sample 208 are African-American, 200 are Hispanic, and 202 are European-American.

Procedure 
Parental consent forms were distributed to all fourth and sixth graders at participating schools. Forms were returned by 70 percent of the targeted students.

Those who obtained parental approval to participate (66 percent of those returning signed forms) were interviewed individually and privately on school grounds by trained undergraduate and graduate female students. Each participant was matched to a single interviewer according to ethnicity. Interviews took approximately 30 minutes.

\section{Measures}

\section{Children's Convoy Mapping Procedure}

The social convoy mapping procedure (Appendix A) originally developed by Kahn and Antonucci (1984) for adults and later adapted for use with children by Levitt and colleagues (1993) provides a useful methodological framework for the study of children's relationships. The convoy mapping procedure has its foundation in the convoy model of social relations. The model is grounded in theories of human attachment and social roles. It provides a framework for studying the development of interpersonal relationships across the lifespan (Antonucci \& Jackson, 1987). The convoy is depicted as a diagram of three concentric circles (bull's eye) surrounding the individual. Each circle represents a level of closeness perceived by the individual between him or her and those people included in the diagram. Children were asked to place those individuals they "love the most and who love [them] the most" in the inner circle. People "who are not quite as close, but who are still important" were located in the middle circle. The outer circle consisted of those "who are not as close as the others, but who are still important." Children were asked to answer six instrumental and emotional support questions once 
they complete their social convoy diagram. Asking the support questions after the convoy diagram is completed instead of during its completion precludes demand characteristics and response biases that may result when pairing a network member and a support question (Levitt, et al., 1993). The support questions are (1) “Are there people you talk to about things that are really important to you?", (2) “Are there people who make you feel better when something bothers you or you are not sure about something?" (3) “Are there people who would take care of you if you were sick?", (4) "Are there people who help you with homework or other work you do for school?", (5) “Are there people who like to be with you and do fun things with you?", and (6) "Are there people who make you feel special or good about yourself?". Internal consistency ( $M$ alpha = $.82)$ and test-retest reliability ( $M$ intraclass $r=.75)$ of social support measures derived from the mapping procedure are high (Levitt et al., 1993).

After answering the support questions the respondents provided information about the roles of individuals included in the circles. The individuals were then assigned codes that will allow their classification. Relationship categories observed include "parents", "siblings", "grandparents", "close family members" (parents and siblings grouped together), "extended family members", and "friends/peers".

\section{Convoy Size and Composition}

The total number of individuals that children included in their convoy maps was assessed. The attribution of codes to these individuals also allowed for a detailed description of convoy size by relationship category, including the number of close family 
members, extended family members, and friends. Close family consists of parents and siblings.

\section{Total Support and Specific Sources of Support}

The support measures are derived by summing the number of functions received from all relevant providers. Total support is the total number of support functions received from all network members who provide support. Specific sources of support are assessed similarly. For example, "Close Family Support" represents the total number of support functions provided by parents and siblings. Specific indices that were used for this study include (a) "Total Support", (b) "Close Family Support", (c) "Parent Support", (d) "Grandparent Support", (e) "Sibling Support", (f) "Extended Family Support", and (g) "Friend Support."

Depressed Affect

The short form version of the Children's Depression Inventory (CDI-S) (Kovacs, 1992) was used to measure depressed affect of the children. The CDI assesses the presence and severity of affective, cognitive, and motivational components of depression and represents childhood depression as a collection of symptoms rather that as a sad, dysphoric mood.

Selection of the short version of the scale is based on its usefulness with nonclinical populations. It consists of 103 -choice items such as "I am sad once in a while", "I am sad many times", "I am sad all the time"; children chose the sentence that best described their feelings within the past two weeks. Scores range from 0 to 20 , with higher scores indicating higher depressed affect. The alpha reliability for the sample is .74 . 
Loneliness was assessed via the Children's Loneliness Scale (Asher, Hymel, \& Reshaw, 1984). It consists of 16 scale items (e.g., "I can find a friend in my class when I need one") and 8 filler items and assesses children's loneliness primarily in school. It employs a 5-choice response format (from "That's always true about me" to "That's not true about me at all"). An abbreviated version was used for this study. The alpha reliability for the sample is .68 .

Self Concept

Self-concept was measured by the Self Perception Profile (Harter, 1985). Only the cognitive, social, and general subscales were used to minimize the length of the interview. For each of the 18 items, children were presented with two descriptors from which they chose the descriptor "most like them". Then, they indicated how true the descriptor was for them (i e., "Is this really true or sort of true for you?"). A sample item is "Some kids are often unhappy with themselves, but other kids are pretty pleased with themselves." Scores range from 1 to 4 with higher scores denoting higher levels of self-concept. The alpha reliability for the sample is .83 .

\section{Results}

Preliminary Pearson's chi square analyses of the sample descriptors indicated no significant differences between the immigrant and nonimmigrant groups by gender $(2, N$ $=782), p=.94$, school level $(1, N=782), p=.37$, or grade $(1, N=782), p=.19$. There was a significant chi square, however, for ethnicity, $\chi^{2}(2, N=782)=57.42, p<.0001$. Thus, ethnicity was included in the analyses together with immigrant status as an 
independent variable. Means and standard deviations for the social network variables are shown in Table 1.

Question 1. To assess the size and composition of social networks of immigrant versus nonimmigrant preadolescents.

A square root transformation of all dependent variables except number of parents was performed before Research Question 1 analyses, due to the skewness of the responses. Differences in network size by immigrant status were assessed with an analysis of variance (ANOVA). The total number of people included in the network was the dependent variable and immigrant status and ethnicity were the independent variables. There was a marginally significant difference by immigrant status, $F(1,776)=3.34, p=$ .068 . Ethnicity proved to be significant, $F(1,776)=11.33, p<.0001$. A Student-Newman-Keuls post hoc test showed European-American and Hispanic-American children to have significantly more people in their networks than African-American children. There were no significant interactions.

A multivariate analysis of variance (MANOVA) was performed to assess differences in network composition of immigrant and nonimmigrant children. The number of persons in the close family, extended family, and friend categories were the dependent variables and immigrant status and ethnicity the independent variables. There were no significant differences in the number of close family members included in the networks. There were differences, however, for the number of extended family members for ethnicity, $F(2,776)=3.64, p<.05$; Caribbean/African-American children included significantly fewer extended family members. Specifically, the difference in ethnicity 
emerged in the number of grandparents included in the network, $F(2,776)=14.80, p<$ .0001 ; European-Americans included significantly more than Hispanics, who included significantly more than Caribbean/African-Americans. The number of extended family members also differed marginally by immigrant status, $F(1,776)=3.16, p=.076$. There was also a difference in number of friends included in the network by ethnicity, $F$ (2, $776)=12.29, p<.0001 ;$ Caribbean/African-American children included significantly fewer friends. There were no significant interactions.

Question 2. To assess the amount and the specific sources of perceived social support in relation to immigrant status

A square root transformation of all dependent variables was performed before Research Question 2 analyses due to the skewness of the responses. Differences in Total Support (the sum of functions received from all relevant providers) was assessed with an ANOVA. The total amount of perceived support was the dependent variable and immigrant status and ethnicity were the independent variables. There were significant effects for immigrant status, $F(1,776)=6.83, p<.01$, and ethnicity, $F(2,776)=7.83, p$ $<.0001$, respectively. Immigrant children received significantly less total support than nonimmigrant children. For ethnicity, European-American children reported significantly more total support. There were no significant interactions.

A MANOVA was performed to assess differences in sources of perceived social support of immigrant and nonimmigrant children. Results revealed a significant difference in Close Family Support for immigrant status only, $F(1,776)=5.60, p<.05$. U.S.-born children perceived more social support from their close family than did 
immigrant children. Specifically, immigrant children receive less Sibling Support than their U.S.-born peers $F(1,776)=6.71, p=.01$. Extended Family Support revealed a marginal effect for immigrant status, $F(1,776)=3.22, p=.073$. Immigrants received marginally less support from grandparents compared to nonimmigrants $F(1,776)=3.27$, $p=.07$. Friend Support was significant for ethnicity only, $F(2,776)=12.90, p<.0001$; European-Americans received significantly more support than Hispanics, who received significantly more support than Caribbean/African-Americans. There were no significant interactions.

Question 3. To assess differences in levels of well-being across immigrant status Differences in levels of well-being across immigrant status were assessed with a MANOVA with Loneliness, Self-Concept, and Depressed Affect as dependent variables and immigrant status and ethnicity as the independent variables. Means and standard deviations for the well-being variables are shown in Table 2 .

There were significant main effects of immigrant status, $F(3,771)=3.61, p<$ .02 , and ethnicity, $F(6,1544)=4.23, p<.0001$. There was also a marginally significant interaction, $F(6,1544)=1.78, p<.10$. Univariate analyses showed Loneliness to be significant by both ethnicity $F(2,773)=4.99, p<.01$ and immigrant status $F(1,773)=$ $6.77, p<.01$. Caribbean/African-American children were significantly lonelier than their peers in other ethnic groups, and immigrants were lonelier than their U.S.-born peers. Self-Concept was significant by ethnicity $F(2,773)=6.52, p<.01$ and marginally significant for immigrant status $F(1,773)=3.29, p=.070$.

European-American children's reports of Self-Concept were significantly higher than 
their peers in other ethnic groups, and immigrant children reported marginally lower levels of Self-Concept. There was an ethnicity by immigrant status interaction for Depressed Affect , $F(2,773)=4.36, p<.05$, along with main effects of immigrant status, $F(1,773)=9.09, p<.01$, and ethnicity, $F(2,773)=5.39, p<.01$. In regard to the interaction, foreign-born Caribbean/African-American children reported the highest levels of Depressed Affect.

Question 4. To assess the extent to which the differences in levels of well-being are a function of perceived social support.

A multiple regression strategy was used to observe the relationship between perceived social support and well-being beyond other variables. The three-step regression included ethnicity, immigrant status, socioeconomic level, gender, and grade in the first block. The second block included close family, extended family, and friend support. The third block included terms representing the interactions of immigrant status by each support variable. Square root transformations were performed on skewed variables to normalize their distribution. Transformed variables included Close Family Support, Extended Family Support, and Friend Support. Results of the regression analyses are presented in Table 3.

In regard to depressed affect, the first block including the demographic variables was significant, $F$ Change $=5.12, p=.0001$, accounting for $3.2 \%$ of the variance. Immigrant status and school economic level were significant predictors of child depressed affect. The block including support from close family, extended family, and friends was also significant, $F$ Change $=2.75, p<.05$, accounting for $1.0 \%$ of the 
variance. Close Family Support was a significant individual predictor of depression. Interactions of immigrant status by each support variable were not significant.

For loneliness, the block including demographic variables was significant, $F$ Change $=4.81, p<.001$, accounting for $3.0 \%$ of the variance. School economic level and grade were significant predictors of loneliness. The block including the support variables was also significant, $F$ Change $=7.93, p<.0001$, accounting for $2.9 \%$ of the variance. Extended Family Support and Friend Support, respectively, were significant predictors of loneliness. The third block including interactions was marginally significant, $F$ Change $=2.45, p<.07$, accounting for $1.0 \%$ of the variance. Immigrant status by Extended Family Support $(p<.06)$ and immigrant status by Friend Support $(p<$ .08 ) were marginally significant individual predictors. Follow-up regressions conducted separately for immigrants and nonimmigrants revealed that extended family support was more significant for immigrant children $(\mathrm{b}=-.20, p<.01)$ than for nonimmigrants $(\mathrm{b}=$ $-.08, p<.08)$; support from grandparents was significant only for immigrant children $(b=$ $-.25, p<.05)$. Friend support was also more significant for immigrants $(b=-.24, p<.01)$ than for nonimmigrants $(\mathrm{b}=-.10, p<.02)$.

For Self-Concept, the block of the regression including the demographic variables was significant, $F$ Change $=9.86, p<.0001$, accounting for $6.0 \%$ of the variance. Ethnicity, school economic level, sex, and grade were significant predictors of Self-Concept. The second block was also significant, $F$ Change $=9.03, p<.0001$, accounting for $3.2 \%$ of the variance. Close Family Support and Friend Support were significant predictors of Self-Concept. Third block interactions were not significant. 


\section{Discussion}

The study addressed four research questions. First, what is the size and composition of social networks of immigrant and nonimmigrant children; second, what is the amount and what are the specific sources of perceived social support in relation to immigrant status; third, are there well-being differences by immigrant status; and fourth, are differences in well-being a function of perceived social support.

Question 1. Network Size and Composition.

The first finding provides marginal results in support of the first hypothesis; immigrant children reported a marginally smaller number of network members than did their U.S.-born peers. As participants were screened and only those with at least an advanced understanding of English as second language were recruited, immigrant participants may have resided in the U.S. for some time before data collection. Thus, this finding may be representative of the change that takes place in immigrant children's networks with time spent in the United States. A more significant difference, in other words, may have been observed with a group of recent immigrants. In regard to ethnicity, African-Caribbean/American children reported a significantly smaller number of network members.

Network composition was then observed by the primary relationship categories. Immigrant and nonimmigrant children did not differ in the number of close family members they included, but there was a marginal difference for extended family. As previously indicated, it is common for the nuclear family to migrate first and for other 
family members to follow. After some time, the first settlers may offer others a secure base to begin their migratory transition.

There were significant differences by ethnicity. African-Caribbean/Americans reported significantly fewer extended family members. In particular, the difference was most pronounced for the number of grandparents, where all groups differed; European-Americans had the most and African-Caribbean/Americans the least. Number of friends in the network also varied by ethnicity, with the African-Caribbean/American group having a significantly smaller number. The marked difference in network composition between African-Caribbean/Americans and other groups deserves further examination in the ethnic differences rubric of social networks studies.

\section{Question 2. Amount and Sources of Support.}

As hypothesized, immigrant children perceived significantly less total support than did nonimmigrants. A closer look revealed a significantly lower level of perceived support from close family. In particular, it is support from siblings that is significantly low, despite there being no differences in network composition for this category. Siblings may play a special role in immigrant families at this developmental stage. They may share the close bonds of family members as well as the dynamics of peer relationships. Further research in this area may benefit from the comparison between preand post- migration sibling relationships.

As hypothesized, immigrant children reported lower levels of support from extended family, although this result was marginally significant. This finding supports previous research on foreign born immigrants' limited sources of support outside the 
home (Golding and Baezconde-Garbanati, 1990). This marginal effect extended to support from grandparents. These reports are congruent with those of network composition. In general, the results suggest that immigrant children experience less support from non-parental family members. This may be a source of distress, given the sense of family interdependence, importance of the extended family, need for kin as a source of emotional support, and the increasing need of support from family previously documented (Gil \& Vega, 1996; Padilla et al., 1988; Keefe et al., 1979).

European-American children reported the highest levels of total support. They also perceived the highest levels of friend support; Hispanic-Americans were intermediate in friend support. Extended family support was not significant for ethnicity, playing an important role only for immigrant status.

\section{Question 3. Differences in Well-Being.}

The hypothesis that immigrant children's levels of well-being are lower than nonimmigrants' is supported, in accordance with some previous research (Kao, 1999). In particular, there was support for the hypothesized higher levels of loneliness and depressed affect for immigrant children. Reduced availability of social support and the demands of immigrant adaptation are likely contributors to their reports of loneliness and depressed affect. In regard to depressed affect, the immigrant status by ethnicity interaction indicated highest levels for the group at highest disadvantage in the combination of network structure and social support - African-Caribbean immigrants. As expected, given the previous research (Harris, 1999; Rumbaut, 1999), self-concept did not vary significantly by immigrant status, although there was a marginal effect. 
Self-concept may be associated with issues not particular to immigration, such as one's looks and physical development. It may also be related to school achievement, where immigrants' levels have been found to be the same or better than that of nonimmigrants. Question 4. Social Support and Well-Being.

The significant lower levels of well-being for the immigrant group were associated with different sources of support. The relationship between immigrant status and depressed affect was supported (Padilla et al., 1996; Rumbaut, 1999). Depressed affect was also predicted by close family support, which was significantly lower for the immigrant group. Loneliness was related to lower levels of extended family and friend support. An interaction effect indicated that a relationship between extended family support and loneliness was present for immigrant children, but absent for nonimmigrant children. This unique relationship between lower levels of extended family support and feelings of loneliness is evidence of the importance of support beyond the close family for non-U.S.-born children. Lack of extended family support at a time of adaptation to a new culture may be partially responsible for such feelings. This was specially true for low support from grandparents. Low friend support predicted loneliness for both immigrants and nonimmigrant, although the link was somewhat more significant for immigrants. Self-concept was not related to immigrant status and the relationship between close family support and self-concept did not differ for immigrants versus nonimmigrant. Thus, limitations in different types of support influence the well-being of immigrant children differently. There is an significant, but intricate relationship between support and well-being for this group. Furthermore, the importance of these types of 
support may be unique to this developmental stage, one that shares properties of both childhood and adolescence.

This study's findings are representative of the relationships that exist between variables of the social world and variables of psychological adjustment. In some cases, the relationships are highly significant, having the power to predict outcomes with a low margin of error. Yet the results are limited to an indication of association between variables, and an assumption of causation is inaccurate.

This study's findings are also limited by the heterogeneity of its participants. The variety of ethnic as well as nationality differences within the sample affect the generalizability of findings. Results for the immigrant group cannot be generalized to children from a specific country of origin. Cultural and ethnic idiosyncrasies responsible for underlying mechanisms may be obscured. In addition, the challenge of generalization is magnified by an elaborate and interesting nexus between race and nationality.

\section{Conclusion}

In sum, findings from this study highlight the importance of family support to the well-being of immigrant preadolescents. Rooted in the convoy model of social support, this study first addressed the most salient attributes of immigrant preadolescents' social networks. Although participants were not recent immigrants, they reported a marginally smaller number of loved ones in their social circles. This result then translated into lower levels of support form family members.

The major contributions of this work are the evidence for lower well-being and the relationship between social support and psychological well-being for non-U.S.-born 
children. Research in the area of social support has grown in recent years, and this study is an attempt to expand its boundaries to include groups less well documented. The importance of close family support as a predictor of depressed affect, the important role that extended family and friend support play in how lonely the immigrant child feels, how the strength between support from grandparents and the child's feelings of isolation are unique to the immigrant group, and how self-concept is influenced by close family support and friend support are just a few of the findings that hold potential importance in explaining the adaptation of immigrant children.

The role that ethnicity plays in the relationship between social support and well-being needs to be explored further. The present findings indicate marked group differences at various dimensions of the observed variables. Immigrants belong to diverse ethnic groups, which may sometimes influence their development depending on their race or immigrant generation. Ethnic minority immigrants may face the cumulative disadvantage of belonging to a particular racial group; one with its own set of challenges in the host culture (Portes \& Zhou, 1993). Elsewhere it has been reported that U.S.-born African-American and Hispanic-American children of immigrants may also experience difficulties with their parents associated with differences in acculturation or acceptance of American customs (Rumbaut, 1995). Second generation Hispanic-American immigrants have also reported cultural stressors such as perception of a closed society not reported by other generations of immigrants (Vega et al., 1995). The observation of immigrant status in conjunction with ethnic background presents itself as a logical and appropriate continuation of the work presented here. 


\section{References}

Achenbach, T. M., \& Edelbrock, C. (1983). Manual for the child behavior checklist and revised child behavior profile. Burlington: University of Vermont, Department of Psychiatry.

Alatorre Alva, S., \& de Los Reyes, R. (1999). Psychosocial stress, internalized symptoms, and academic achievement of Hispanic adolescents. Journal of Adolescent Research, 14(3),343-358.

Antonucci, T. C. (1990). Social supports and social relationships. In R. H. Binstock \& L. K. George (Eds.), The Handbook of Aging and the Social Sciences. New York: Academic Press.

Antonucci, T. C., \& Jackson, J. S. (1987). Social support, interpersonal efficacy and health: A life course perspective. In C. Tensen, L. Laura, and B. Edelstein (Eds.), Handbook of Clinical Gerontology: Vol 164. (pp. 291-311). New York: Pergamon Press.

Aronowitz, M. (1984). The social and emotional adjustment of immigrant children: A review of the literature. International Migration Review, 18, 237-257.

Asher, S. R., Hymel, S., \& Renshaw, P. D. (1984). Loneliness in children. Child Development, 55, 1459-1464.

Baptiste, D. A. (1993). Immigrant families, adolescents, and acculturation: Insight for therapists. Marriage and Family Review, 19, 341-363.

Belle, D. (1989). Gender differences in children's social networks and supports. In D. Belle (Ed.), Children's Social Networks and Social Supports (pp. 173-190). New York: Wiley.

Booth, A., Crouter, A. C., \& Landale, N. (1997). Immigration and the Family. New Jersey: Lawrence Earlbaum Associates.

Bronfenbrenner, U. \& Crouter, A. C. (1983). The evolution of environmental models in developmental research. In W. Kessen (Ed.), Handbook of Child Psychology: Vol. 1. History, theory, and methods (pp. 357-414). New York: Wiley.

Britannica Online. (2000). Available: http://www.britannica.com/ 
Canino, I. A., Early, B. F., \& Rogler, L. H. (1980). The Puertorican child in New York City: Stress and mental health. New York: Hispanic Research Center.

Cochran, M., Larner, M. Riley, D., Gunnarsson, \& Henderson, C. R. (1990). Extending families: The social networks of parents and their children. New York: Cambridge University Press.

Cornille, T. A., \& Brotherton, W. D. (1993). Applying the developmental family therapy model to issues of immigrant families. Marriage and Family Review, 19, 325-340.

Day, J. C. (1996). Population Projections of the United States by Age, Sex, Race, and Hispanic Origin: 1995 to 2050. U.S. Bureau of the Census, Current Populations Reports, 25-1130. Washington, DC: U.S. Government Printing Office.

De Santis, L., \& Ugarriza, D. N. (1995). Potential for intergenerational conflict in Cuban and Haitian immigrant families. Archives of Psychiatric Nursing, 9, 354-364.

Dunn, J. (1993). Young children's close relationships: Beyond attachment. Beverly Hills, CA: Sage.

Eisenbruch, M. (1988). The mental health of refugee children and their cultural development. International Migration Review, 22, 282-300.

Felner, R. D., Brand, S., DuBois, D. L., Adan, A. M., Mulhall, P. F., \& Evans, E. G. (1995). Socioeconomic disadvantage, proximal environmental experiences, and socioemotional and academic adjustment in early adolescence: Investigation of a mediated effects model. Child Development, 66, 774-792.

Fuligni, A. J. (1998). The adjustment of children from immigrant families. Current Directions in Psychological Science, 7, 99-103.

Gil, A. G. \& Vega, W. A. (1996). Two different worlds: Acculturation stress and adaptation among Cuban and Nicaraguan families. Journal of Social and Personal Relationships, 13 (3), 435-456.

Gil, A. G., Vega, W. A., \& Biafora, F. (1998). Temporal influences of family structure and family risk factors on drug use initiation in a multiethnic sample of adolescent boys. Journal of Youth and Adolescence, 27(3), 373-393.

Golding, J. M. \& Baezconde-Garbanati, L. A. (1990). Ethnicity, culture, and social resources. American Journal of Community Psychology, 18 (3), 465-486. 
Guerra, R. G., \& Jagers, R. (1998). The Importance of Culture in the Assessment of Children and Youth. In V. C. McLoyd, \& L. Steinberg (Eds.), Studying Minority Adolescents (pp. 167-182). New Jersey: Lawrence Earlbaum Associates.

Harris, K. M. (1999). The health status and risk behaviors of adolescents in immigrant families. In D. J. Hernandez (Ed.), Children of Immigrants (pp. 286-347). Washington, DC: National Academy Press.

Harrison, A. O., Wilson, M. N., Pine, C. J., Chan, S. Q., \& Buriel, R. (1990). Family ecologies of minority children. Child Development, 61, 347-362.

Harter, S. (1985). Manual for the Self-Perception Profile for Children. University of Denver.

Hernandez, D. J., \& Charney, E. (1998). From generation to generation: The health and well-being of children in immigrant families. Committee on The Health and Adjustment of Immigrant Children and Families, National Research Council and Institute of Medicine. Washington, DC: National Academy Press.

Igoa, C. (1995). The Inner World of the Immigrant Child. New York: St. Martin's Press.

James, D. C. S. (1997). Coping with a new society: The unique psychosocial problems of immigrant youth. Journal of School Health, 67(3), 98-102.

Kahn, R. L., \& Antonucci, T. C. (1984). Social support of the elderly: Family/friends/professionals (Report No. AGO1632). Washington, D.C.: National Institute of Aging.

Kao, G. (1999). Psychological well-being and educational achievement among immigrant youth. In D. J. Hernandez (Ed.), Children of Immigrants: Health, Adjustment, and Public Assistance (pp. 410-477). Washington, DC: National Academy Press.

Keefe, S. E., Padilla, A. M., \& Carlos, M. L. (1979). The Mexican-American extended family as an emotional support system. Human Organization, 38(2), 144-152.

Kopala, M., Esquivel, G. B., Baptiste, L. (1994). Counseling approaches for immigrant children: Facilitating the acculturative process. School Counselor, 41, 352-359.

Kovacs, M. (1992). Children's Depression Inventory Manual. North Tonawanda, NY: Multi-Health Systems. 
Laosa, L. (1989). Psychosocial stress, coping, and the development of Hispanic immigrant children. Princeton, NJ: Educational Testing Service.

Levitt, M. J., \& Guacci- Franco, N., \& Levitt, J. L. (1993). Convoys of social support in childhood and adolescence: Structure and function. Developmental Psychology, 29, 811-818.

Levitt, M. J., Crooks, N. A., Bustos, G. A., Santos J. D., Telan, P., Silver, M. E., Branscum, E., \& Levitt, J. L. (1998). The social ecology of well-being in middle childhood. Paper presented at the meeting of the American Psychological Association, San Francisco.

Martin, P., \& Midgley, E. (1994). Immigration to the United States: Journey to an uncertain destination. Population Bulletin, 49 (1), 2-45.

Mena, F. J., Padilla, A. M., \& Maldonado, M. (1987). Acculturative stress and specific coping strategies among immigrant and later generation college students. Hispanic Journal of Behavioral Sciences, 9, 207-225.

Morrison, G. M., Laughlin, J., San Miguel, S., Smith, D. C., \& Widaman, K. (1996). Sources of support for school related issues: Choices of Hispanic adolescents varying in migrant status. Journal of Youth and Adolescence, 26(2), 233-251.

Munroe-Blum, H., Boyle, M. H., Offord, D. R., \& Kates, N. (1989). Immigrant children: Psychiatric disorder, school performance, and service utilization. American Journal of Orthopsychiatry, 59 (4), 510-519.

Padilla, A. M., Cervantes, R. C., Maldonado, M., \& Garcia R. C. (1988). Coping responses to psychological stressors among Mexican and Central American immigrants. Journal of Community Psychology, 16, 418-427.

Pawliuk, N., Gritzenko, N., Chan-Yip, A., Gantous, P., Mathew, J., \& Nguyen, D. (1996). Acculturation style and psychological functioning in children of immigrants. American Journal of Orthopsychiatry, 66(1), 111-121.

Portes, A., \& Zhou, M. (1993). The new second generation: Segmented assimilation and its variants. Annals of the American Academy of Political and Social Science, 530, 74-96.

Rousseau, C., Drapeau, A., \& Corin, E. (1996). School performance and emotional problems in refugee children. American Journal of Orthopsychiatry, 66, 239-251. 
Rumbaut, R. (1995). The crucible within: Ethnic identity, self-esteem, and segmented assimilation among children of immigrants. International Migration Review, $28,748-794$.

Rumbaut, R. G. (1997). Ties that bind: Immigration and immigrant families in the United States. In Booth, A. , Crowter, A. C., \& Landale, N. (Eds.), Immigration and the Family: Research and Policy on U.S. Immigrants (pp. 3-46). Mahwah, NJ: Erlbaum.

Rumbaut, R. G. (1999). Passages to adulthood: The adaptation of children of immigrants in Southern California. In D. J. Hernandez (Ed.), Children of Immigrants: Health, Adjustment, and Public Assistance. Washington, DC: National Academy Press.

Short, K. H., \& Johnston, C. (1997). Stress, maternal distress, and children's adjustment following immigration: The buffering role of social support. _Journal of Consulting and Clinical Psychology, 65(3), 494-503.

Shuval, J. T. (1982). Migration and stress. In L. Goldberg \& S. Breznitz (Eds.), Handbook of stress: Theoretical and clinical aspects (pp. 677-691). New York: The Free Press.

Szapocznik, J., Kurtines, W. M., \& Fernandez, T. (1980). Bicultural involvement and adjustment in Hispanic-American youths. International Journal of Intercultural Relations, 4, 353-365.

Upped, S. (1998). A typology of risk and resilience among Latino middle school youth. Paper presented at the annual meeting of the American Psychological Association, August 14-18, in San Francisco, CA.

U.S. Bureau of the Census. (1994). Statistical Abstract of the United States: 1994. Washington, DC: U.S. Government Printing Office.

Vegas, W. A., Khoury, E. L., Zimmerman, R. S., \& Gill, A. G. (1995). Cultural conflicts and problem behaviors of Latino adolescents in home and school environments. Journal of Community Psychology, 23, 167-179.

Vega, W. A., \& Rumbaut, R. G. (1991). Ethnic minorities and mental health. Annual Review of Sociology, 17, 350-383.

Weinberg, A. (1979). Mental health aspects of voluntary migration. In C. Zwingman \& M. Pfister-Ammende (Eds.), Uprooting and after... (pp. 110-120). New York: Springer-Verlag. 
Table 1.

Network Composition and Support

\begin{tabular}{|c|c|c|c|c|c|c|c|c|c|}
\hline \multirow[b]{3}{*}{ Network Variable } & \multicolumn{4}{|c|}{ Immigrant Status } & \multicolumn{5}{|c|}{ Ethnicity } \\
\hline & \multicolumn{2}{|c|}{ Non-U.S.-born } & \multicolumn{2}{|c|}{ U.S.-born } & \multicolumn{2}{|c|}{ African } & Hispanic & \multicolumn{2}{|c|}{ European } \\
\hline & $\underline{\mathrm{M}}$ & $\underline{\mathrm{SD}}$ & $\underline{\mathrm{M}}$ & $\underline{\mathrm{SD}}$ & $\underline{\mathrm{M}}$ & $\underline{\mathrm{SD}}$ & $\underline{\mathrm{SD}}$ & $\underline{\mathrm{M}}$ & $\underline{\mathrm{SD}}$ \\
\hline \multicolumn{10}{|l|}{ Composition } \\
\hline Total number & 11.83 & $(6.46)$ & 12.67 & $(7.34)$ & 10.62 & $(5.32)$ & $13.00(7.92)$ & 13.79 & $(7.42)$ \\
\hline Close Family & 4.47 & $(1.62)$ & 4.86 & $(1.98)$ & 4.58 & $(1.80)$ & $4.68(1.91)$ & 5.19 & $(1.98)$ \\
\hline Parents & 2.01 & $(0.43)$ & 1.97 & $(0.58)$ & 1.89 & $(0.61)$ & $2.00(0.54)$ & 2.05 & $(0.49)$ \\
\hline Siblings & 1.26 & $(1.02)$ & 1.58 & $(1.45)$ & 1.85 & $(1.55)$ & $1.41(1.27)$ & 1.29 & $(1.24)$ \\
\hline Extended Family & 4.68 & $(3.87)$ & 5.12 & $(4.12)$ & 4.39 & $(3.87)$ & $5.04(3.95)$ & 5.69 & $(4.32)$ \\
\hline Grandparents & 1.20 & $(1.26)$ & 1.33 & $(1.25)$ & 0.84 & $(0.91)$ & $1.26(1.20)$ & 1.84 & $(1.43)$ \\
\hline Friends & 2.92 & $(3.53)$ & 2.63 & $(2.98)$ & 1.78 & $(2.35)$ & $3.04(3.42)$ & 3.20 & $(3.19)$ \\
\hline \multicolumn{10}{|l|}{ Support } \\
\hline Total Support & 4.64 & $(1.43)$ & 5.03 & $(1.61)$ & 4.61 & $(1.56)$ & $4.87 \quad(1.48)$ & 5.41 & $(1.65)$ \\
\hline Close Family & 3.00 & $(0.83)$ & 3.23 & $(0.92)$ & 3.08 & $(0.95)$ & $3.14 \quad(0.88)$ & 3.35 & $(0.88)$ \\
\hline Parents & 2.58 & $(0.69)$ & 2.65 & $(0.75)$ & 2.44 & $(0.76)$ & $2.61 \quad(0.71)$ & 2.88 & $(0.69)$ \\
\hline Siblings & 1.22 & $(1.05)$ & 1.51 & $(1.59)$ & 1.54 & $(1.22)$ & $1.42 \quad(1.13)$ & 1.39 & $(1.14)$ \\
\hline Extended Family & 2.37 & $(1.63)$ & 2.64 & $(1.83)$ & 2.41 & $(1.84)$ & $2.51 \quad(1.70)$ & 2.85 & $(1.82)$ \\
\hline Grandparents & 1.10 & $(1.12)$ & 1.29 & $(1.26)$ & 0.92 & $(1.14)$ & $1.16 \quad(1.15)$ & 1.74 & $(1.29)$ \\
\hline Friends & 1.55 & $(1.60)$ & 1.62 & $(1.66)$ & 1.13 & $(1.45)$ & $1.67(1.59)$ & 2.05 & $(1.80)$ \\
\hline
\end{tabular}


Table 2.

Well-Being Means and Standard Deviations

\begin{tabular}{|c|c|c|c|c|c|c|c|c|c|c|}
\hline \multirow[b]{3}{*}{ Well-Being } & \multicolumn{4}{|c|}{ Immigrant Status } & \multicolumn{6}{|c|}{ Ethnicity } \\
\hline & \multicolumn{2}{|c|}{ Non-U.S.-born } & \multicolumn{2}{|c|}{ U.S.-born } & \multicolumn{2}{|c|}{ African } & \multicolumn{2}{|c|}{ Hispanic } & \multicolumn{2}{|c|}{ European } \\
\hline & $\underline{\mathrm{M}}$ & $\underline{\mathrm{SD}}$ & $\underline{\mathrm{M}}$ & $\underline{\mathrm{SD}}$ & $\underline{M}$ & $\underline{\mathrm{SD}}$ & $\underline{M}$ & $\underline{\mathrm{SD}}$ & $\underline{\mathrm{M}}$ & $\underline{\mathrm{SD}}$ \\
\hline Depression & 1.26 & 0.29 & 1.20 & 0.26 & 1.24 & 0.29 & 1.22 & 0.27 & 1.17 & 0.23 \\
\hline Loneliness & 1.98 & 0.76 & 1.87 & 0.71 & 2.00 & 0.78 & 1.86 & 0.66 & 1.81 & 0.73 \\
\hline Self-Concept & 3.02 & 0.51 & 3.11 & 0.50 & 3.02 & 0.49 & 3.03 & 0.51 & 3.24 & 0.49 \\
\hline
\end{tabular}


Table 3.

Hierarchical Multiple Regressions of Immigrant Status and Support as Predictors of Well-Being

\begin{tabular}{|c|c|c|c|c|c|c|}
\hline \multirow[b]{2}{*}{ Predictors } & \multicolumn{2}{|c|}{ Depression } & \multicolumn{2}{|c|}{ Loneliness } & \multicolumn{2}{|c|}{ Self-Concept } \\
\hline & $\bar{b}$ & $r^{2}$ & $\bar{b}$ & $r^{2}$ & $\bar{b}$ & $\overline{r^{2}}$ \\
\hline \multicolumn{7}{|l|}{ Step 1} \\
\hline Ethnicity & -.05 & $<.01$ & -.05 & $<.01$ & $.09^{*}$ & .01 \\
\hline Immigrant Status & $-.10^{* *}$ & .01 & -.06 & $<.01$ & .06 & $<.01$ \\
\hline School Economic Level & $-.11^{* *}$ & .01 & $-.11 * *$ & .01 & $.16^{* * * *}$ & .02 \\
\hline Sex & $<-.01$ & $<.01$ & -.04 & $<.01$ & $.07^{*}$ & .01 \\
\hline Grade & -.07 & $<.01$ & $-.08 *$ & .01 & $.07 *$ & .01 \\
\hline
\end{tabular}

Step 2

$\begin{array}{lcccccc}\text { Close Family Support } & -.10^{* *} & .01 & -.04 & <.01 & .14^{* * * *} & .02 \\ \text { Extended Fam. Support } & <-.01 & <.01 & -.11^{* *} & .01 & .05 & <.01 \\ \text { Friend Support } & .02 & <.01 & -.13^{* * *} & . .02 & .08^{*} & .01\end{array}$

Step 3

\begin{tabular}{lcccccc} 
Imm. Stat. X Cl. Fam. S. & .03 & $<.01$ & .03 &.$<.01$ & -.04 & $<.01$ \\
Imm. Stat. X Ext. Fam. S. & .12 & $<.01$ & $.20^{+}$ & $<.01$ & .02 & $<.01$ \\
Imm. Stat X Friend Sup. & .11 & $<.01$ & $.15^{+}$ & $<.01$ & -.09 & $<.01$ \\
\hline
\end{tabular}

Note. $b=$ standardized beta weight; $r^{2}=$ the proportion of variance accounted for by each predictor.

${ }^{* * * *} p<.0001 ;{ }^{* * *} p<.001 ;{ }^{* *} p<.01 ;{ }^{*} p<.05 ;{ }^{+} p<.08$ 
Appendix A

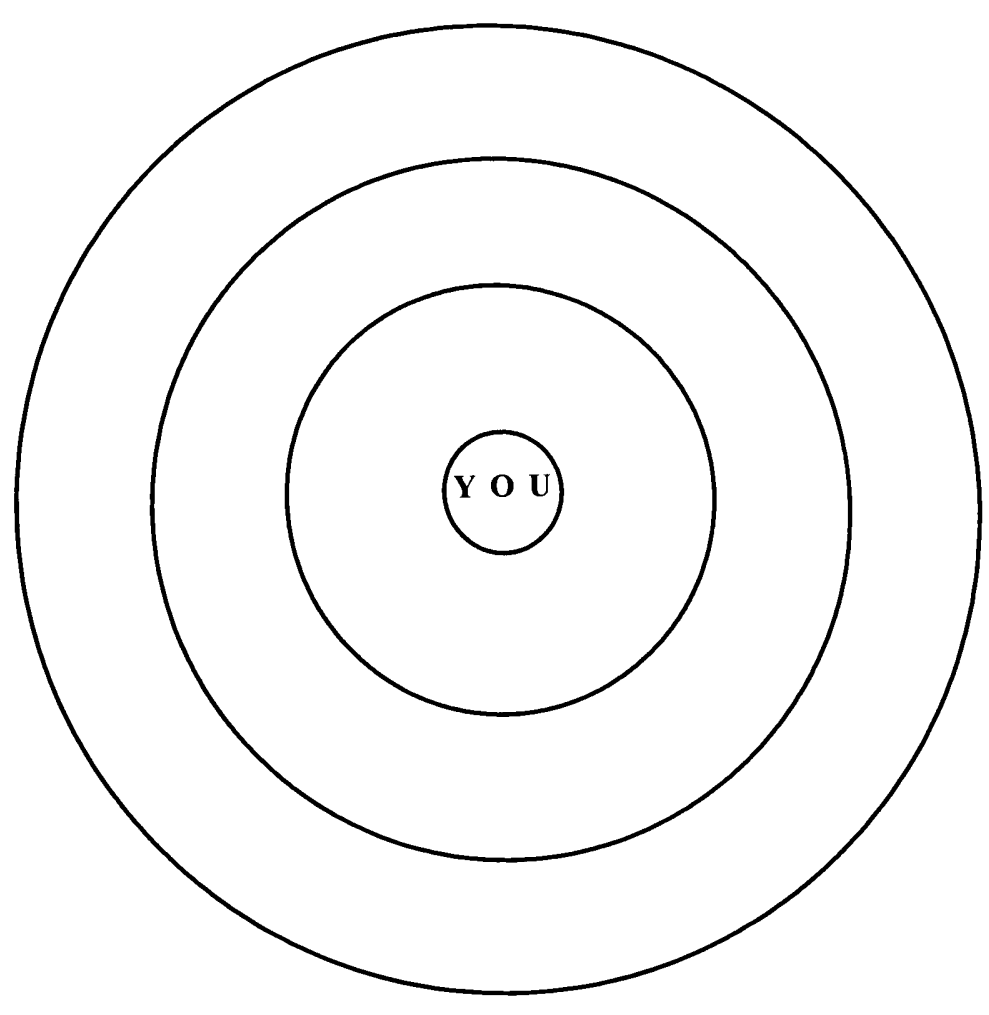

